\title{
Breast Imaging of Transgender Individuals: A Review
}

\author{
Emily B. Sonnenblick ${ }^{1} \cdot$ Ami D. Shah ${ }^{1} \cdot$ Zil Goldstein $^{2} \cdot$ Tamar Reisman $^{3}$
}

Published online: 18 January 2018

(c) The Author(s) 2018. This article is an open access publication

\begin{abstract}
Purpose This review will inform radiologists about the evidence base regarding radiographic imaging for transgender individuals and considerations for providing culturally sensitive care for this population.

Findings Transgender individuals are increasingly referred for both screening and diagnostic breast imaging. It is important that the clinic environment is welcoming, the medical staff utilize accepted terminology and patients are able to designate their gender and personal history to ensure appropriate care. Hormone and surgical treatments used for transition by many transgender women and men may change the approach to imaging.

Summary Although not yet evidence-based, screening mammography is currently suggested for transgender women with risk factors, including those receiving
\end{abstract}

This article is part of the Topical collection on Breast Imaging.

Emily B. Sonnenblick

Emily.sonnenblick@mountsinai.org

Ami D. Shah

Ami.shah@mountsinai.org

Zil Goldstein

Zil.goldstein@mountsinai.org

Tamar Reisman

Tamar.reisman@exchange.mssm.edu

1 Department of Radiology, Icahn School of Medicine at Mt Sinai, One Gustav Levy Place, New York, NY 10029, USA

2 Department of Medicine, Center for Transgender Medicine and Surgery at Mt. Sinai, 275 Seventh Avenue, New York, NY 10011, USA

3 Department of Medicine, Icahn School of Medicine at Mt. Sinai, 275 Seventh Avenue, New York, NY 10011, USA hormone treatment over 5 years. The risk for breast cancer in transgender individuals is still being defined.

Keywords Transgender · Breast · Mammography · Transsexual $\cdot$ Screening

\section{Introduction}

It is estimated that from 8 to 25 million individuals worldwide now identify as transgender [1 •*]. The increasing use of cross hormone treatment and sex reassignment surgery to affirm gender identity in this population poses special considerations for the radiologist. Some clinical scenarios translate seamlessly from the cisgender population to the transgender patient. For instance, when a transgender patient is referred for diagnostic imaging for a breast complaint such as a palpable mass, the breast imager will generally employ the same protocols used for nontransgender individuals. However, other scenarios are more complicated. In particular, there is a lack of clarity with regards to indications for breast cancer screening in transgender women.

In this paper, we will present indications for diagnostic breast imaging in the transgender population, show expected radiographic findings, and provide an evidencebased review of the current recommendations for breast cancer screening in transgender individuals based on relative risks for cancer derived from both retrospective and cohort studies. We will also outline practical changes that should be considered to provide culturally sensitive health care to this population. A conclusion that will emerge from this review is that there remains a need for prospective longitudinal follow-up of transgender individuals electing 
breast cancer surveillance; a description of and a means to refer patients to one such registry will be presented.

\section{Definitions/Terminology}

Transgender is an adjective used to describe an individual whose gender does not correspond to the one assigned to them at birth. It is independent of genotype, sexual orientation, and behavior. While gender assigned at birth is assessed by inspection of genitalia, gender identity arises from an individual's internal sense of being male or female or something else. Individuals assigned male sex at birth who desire to live as female (transgender women, male to female, MTF) or assigned female sex at birth who desire to live as male (transgender men, female to male, FTM) may take steps to alter their outward appearance to align with their gender identity. Transition refers to the process of changing gender expression or physical appearance to align with gender identity. Gender reassignment refers to steps taken to permanently alter one's phenotype and can be achieved by hormone treatment and surgery. Cisgender and non-transgender refer to people whose gender and gender expression aligns with that assigned to them at birth [2]. Table 1 gives a breakdown of each term and definition.

\section{Cultural Sensitivity}

Due to stigma and discrimination, transgender individuals have suffered from lack of access to competent medical care $[3,4]$. Given the growing desire among health-care professionals to improve access for the transgender community, it is critical for those in the medical community to develop methods for delivering culturally sensitive care in a welcoming environment [5]. Intake forms should allow the patient to self-identify gender, their preferred name, pronoun, and information about gender affirming medical or surgical treatment. This will allow for more complete and accurate information to be entered into standard data fields in medical records thus facilitating delivery of culturally sensitive care and allowing providers to address health care concerns specific to this population of patients which might otherwise be overlooked. Centers that embrace diversity should avoid gender-specific signage (e.g., Women's Imaging Center). Bathroom facilities should be gender neutral. Privacy may be ensured by providing private changing rooms or allowing the patient to change in the exam room.

\section{Medical Hormone Treatment}

\section{Transgender Women}

An essential element of transition for transgender women is breast development. Transgender women may be treated with estrogen for feminization. In addition to estrogen, agents with antiandrogen activity such as spironolactone may be used to suppress testosterone $[6,7 \bullet]$.

Breast development secondary to a physiologic estrogen surge in natal girls has been categorized into five Tanner stages of pubertal development [8]. Transgender women experience muted Tanner stages. There is an initial development of a subareolar breast bud at 3-6 months followed by further enlargement and development of the breast. Maximal breast growth is realized at 2-3 years in our experience. Figure 1 shows heterogeneous breast tissue in a mammogram from a transgender woman treated with cross-sex hormones. Breast size and tissue composition following estrogen treatment varies for each individual. [9•] Transgender women are unlikely to reach Tanner stage 5 [6]. The degree of breast development seems to be independent of type and dose of hormone treatment [9•]. Adding progestins to estrogen does not appear to alter breast size [9•]. Approximately $60 \%$ of trans women seek

Table 1 Definitions/Terminology

\begin{tabular}{ll}
\hline Term & Definition \\
\hline Gender identity & Arises from an individual's internal sense of being male or female or something else \\
Transgender & Adjective to describe an individual whose gender does not align with that assigned to them at birth \\
Transgender woman & A person who was assigned male sex at birth and identifies as female \\
Transgender man & A person who was assigned female sex at birth and identifies as male \\
$\begin{array}{l}\text { Transition } \\
\text { Gender reassignment }\end{array}$ & $\begin{array}{l}\text { Refers to steps taken to alter outward appearance to align with gender identity } \\
\text { surgery }\end{array}$ \\
Cisgender or non- & Adjectives to describe a person whose gender and gender expression aligns with that assigned to them at birth \\
transgender &
\end{tabular}


breast augmentation surgery regardless of the type of estrogen used for feminization [9•, 10]. Augmentation performed by established surgical standards in the U.S. employs silicone or saline implant in pre-pectoral or retropectoral location. While illegal in the U.S., some individuals may have had free injections of a number of substances such as free liquid silicone for purposes of augmentation.

\section{Transgender Men}

Transgender men may be treated with testosterone for masculinization and elect surgery to create a male chest contour.

Testosterone is delivered by intramuscular injection or by transdermal patch, gel, or implant [6, 7•]. Progestins may be added to curtail menses and prevent endometrial hyperplasia. Transgender males taking testosterone will demonstrate serum testosterone levels in the mid to normal male range. In our personal experience, serum estradiol levels may be maintained in post-menopausal female reference range. Some studies have shown estradiol levels above normal male levels in $71 \%$ of transgender men at 6 months of treatment [11]. The potential for elevated estrogen has been hypothesized to reflect peripheral aromatization of circulating testosterone [12].

Transgender men who elect surgical breast removal, referred to as "top surgery", may have residual breast tissue if the surgical procedure consists of contouring of the chest and nipple sparing. It is generally agreed that transgender male patients who undergo breast removal are at very low risk of developing breast cancer. Models for breast cancer risk reduction following simple mastectomy are derived from high-risk cisgender women. It has been observed that there is less than $2 \%$ risk for breast cancer in

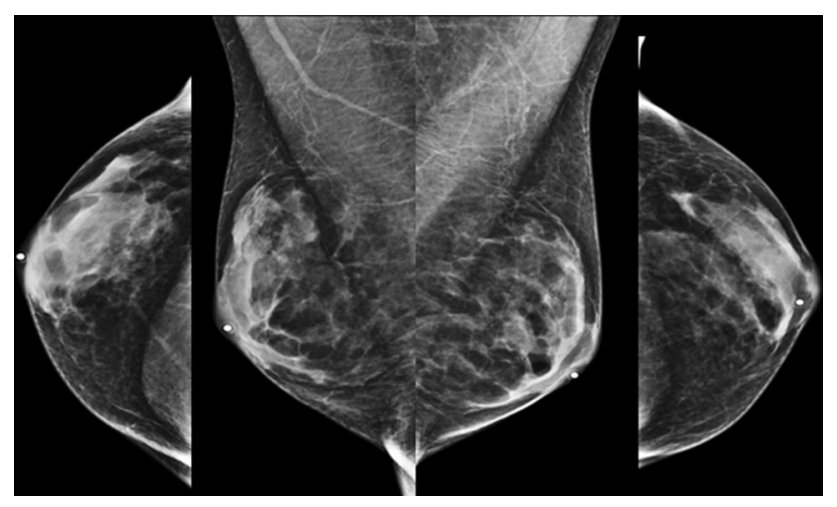

Fig. 1 A 61-year-old transgender woman treated with estradiol and spironolactone for over 10 years. Standard CC and MLO views from her screening mammogram show normal heterogeneously dense breasts cisgender women at increased hereditary risk who have prophylactic mastectomy [13].

\section{Histologic Changes from Hormone Treatment}

\section{Transgender Women}

A mildly elevated ratio of estrogen to progesterone may normally occur in cisgender males during infancy, adolescence and advanced age [14]. This causes variable degrees of proliferation of ductal epithelium which is visualized radiographically as dense tissue centered behind and extending from the nipple referred to as gynecomastia [15]. Males with prostate cancer treated with androgen deprivation develop heterogeneously dense breast tissue referred to as diffuse gynecomastia. This correlates heterogeneously dense tissue correlates histologically with moderate acinar and lobular development [16]. The histologic effect of high levels of estrogen utilized for transition from male to female, unlike gynecomastia, includes development of ducts, lobules and acini histologically identical to cisgender women. Pseudolactational changes have also been described [16]. Figure 2 shows an example of lobule formation and pseudolactational changes in the breast biopsy from a transgender woman. We have also observed lobular development similar to a pre-pubertal breast in the setting of estrogen treatment of transgender females [17].

\section{Transgender Men}

Histologic changes due to progesterone or androgen given in the setting of female to male transition have been inconsistent between studies. Slagter's group looked at histology from 23 trans men treated with injectable testosterone and observed reduced glandular tissue and increased fibrous connective tissue similar to involutional changes observed in post-menopausal women [18]. However, fibrocystic lesions such as cysts, adenosis and duct and lobular hyperplasia found in post-menopausal women were rarely observed in transgender male breast tissue [18]. There are also immunohistochemical differences in the breast tissue of transgender men [19]. Increased fibrous stroma and lobular atrophy have been observed in transgender men receiving long-term testosterone [19]. In another study, only microcalcifications and no other significant changes in breast histology and immunochemistry were noted in mastectomy specimens from 29 transgender men on long-term androgens [20].

Finally, the largest study of mastectomy specimens from 100 transgender males - who were of average age 28 and received androgens for 2-9 years prior to surgery-showed 

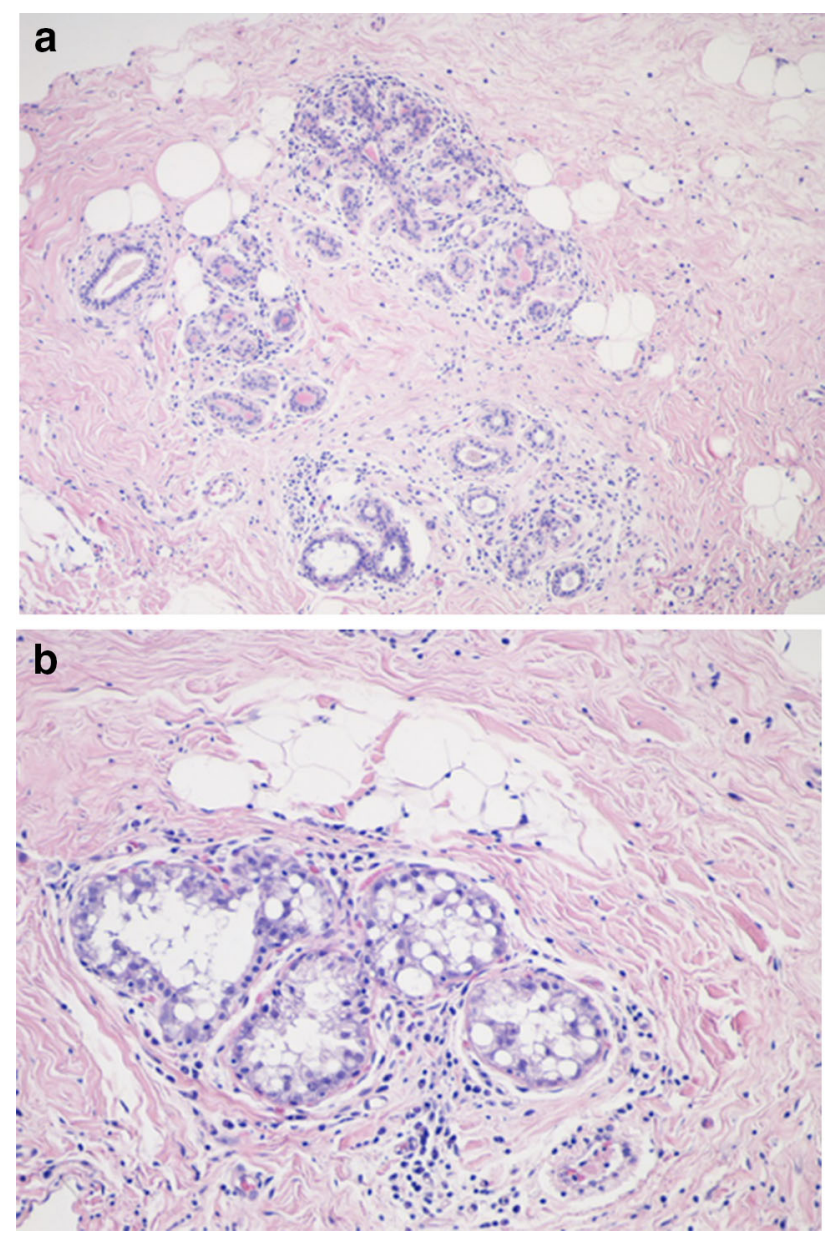

Fig. 2 Histology from the breast of a 55-year-old transgender woman treated with cross-sex hormones since age 19. a Lobule formation ( $\mathrm{H}$ and $\mathrm{E}$ stain at $\times 100$ magnification). b Pseudolactational changes ( $\mathrm{H}$ and $\mathrm{E}$ stain at $\times 200$ magnification)

markedly reduced glandular tissue and proliferation of fibrous stroma in $93 \%$ of cases [21]. These investigators observed fibrocystic lesions in 34 cases and 2 fibroadenomas. Of interest, there were no cases of atypical hyperplasia, in situ carcinoma or features of gynecomastia. [21]

\section{Imaging Appearance}

\section{Transgender Women}

Cross-sex hormone treatment for transgender women causes development of ductal epithelium and lobules which vary in distribution and density between individuals. The same breast pathology that occurs in natal women should be expected in transgender women. There are reports of benign entities such as fibroadenomas [22, 23], lipomas and angiolipoma [24] as well as malignancies including a malignant phyllodes tumor [25] imaged in transgender women treated with cross hormone therapy [26].

A Belgian series assessed 50 transgender women who were at least 6 months post-sex reassignment surgery with screening mammography and ultrasound [27]. In this series, $94 \%$ of transgender female patients were on estrogen therapy; however, the duration of hormone treatment was not recorded. Of these 50 patients, $60 \%$ were judged to have over $25 \%$ dense tissue. There was a significant correlation between degree of breast density on mammography and ultrasound. A single fibroadenoma, several cysts, and two lipomas were detected by ultrasound. Imaging features of these benign lesions were identical to those in cisgender women. Figure 3 shows a group of indeterminate calcifications found on a screening mammogram which underwent biopsy which yielded fibrocystic changes in our practice.

Diagnostic imaging using mammography, ultrasound or MRI is the same in transgender and non-transgender women. Palpable abnormalities, in the absence of free injected silicone, can be evaluated with mammography and ultrasound. Figure 4 shows palpable benign duct ectasia with massive dilated ducts containing debris demonstrated on both mammogram and ultrasound. While bilateral clear nipple discharge is a physiologic finding, unilateral clear or bloody discharge may warrant imaging with mammography followed by breast ultrasound for patients over age 30 . As with cisgender women, initial imaging for pathologic nipple discharge or palpable abnormality using ultrasound is suggested for those under age 30 [28].

In our experience, immature lobules similar to those found in adolescent breast tissue were noted in a transgender women at age 65 who had been taking estrogen for 13 years [17]. Therefore, it is theoretically possible that breast tissue may remain immature and sensitive to ionizing radiation in transgender women who start hormone treatment as adults. Further study is needed to validate this hypothesis and may influence future recommendations for age at which to start with breast ultrasound verses mammography in this population.

As with cisgender patients, breast implants are imaged with standard oblique and craniocaudal views and Eklund displaced views. Breast augmentation by direct injection of particles such as silicone, mineral oil, liquid paraffin, or petrolatum jelly presents a special challenge for imaging. This material migrates in the fat and muscle resulting in masses termed sclerosing lipogranulomas [29-32]. Breast lumps, inflammation, pain and physical disfiguration cause individuals to seek medical care. Fibrosis and granulomas obscure normal tissue on mammography and ultrasound. On mammography these free particle injections present as numerous diffuse round and irregular high-density masses which represent fibrotic 

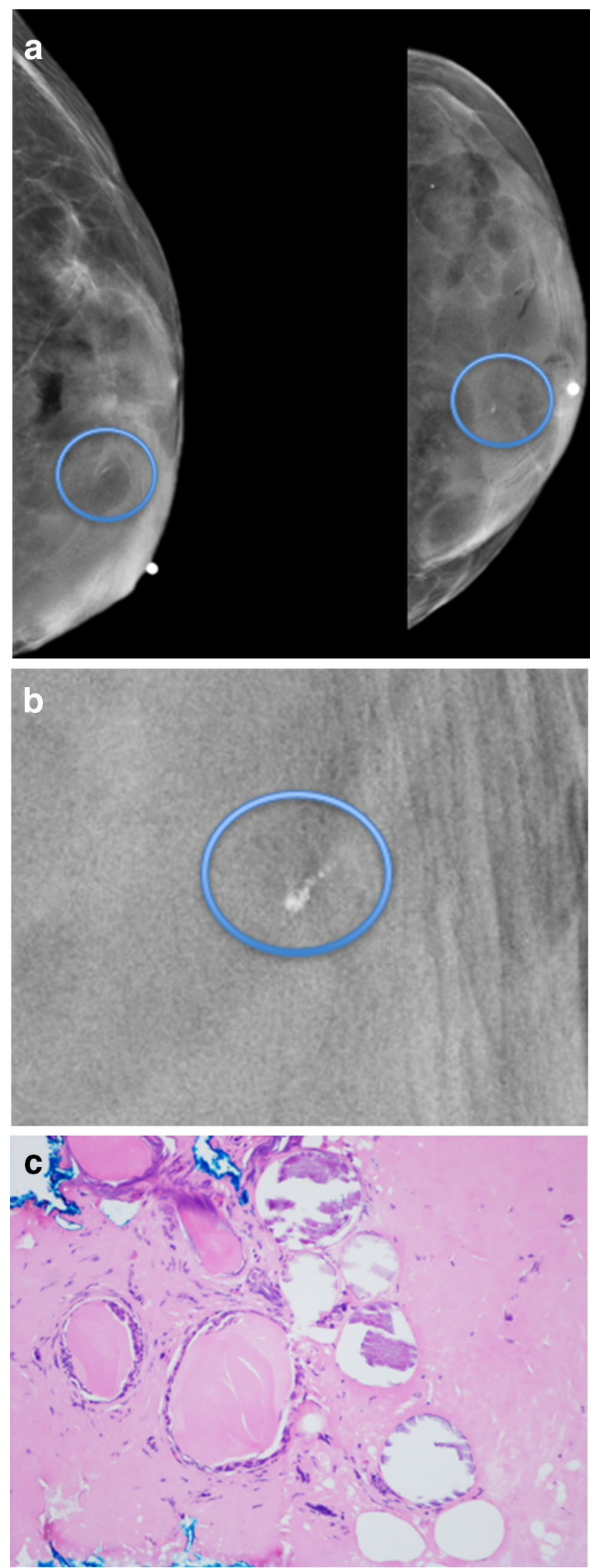

4Fig. 3 A 57-year-old transgender woman treated with estrogen for 37 years. a Left breast mammogram shows extremely dense breast tissue containing a group of calcifications (circled). b Magnified view shows pleomorphic calcifications. c Histopathology from stereotactic biopsy shows tangential section of epithelial lined cystic ducts in fibrous stroma ( $\mathrm{H}$ and $\mathrm{E}$ stain $400 \mathrm{X})$. Findings are consistent with fibrocystic changes
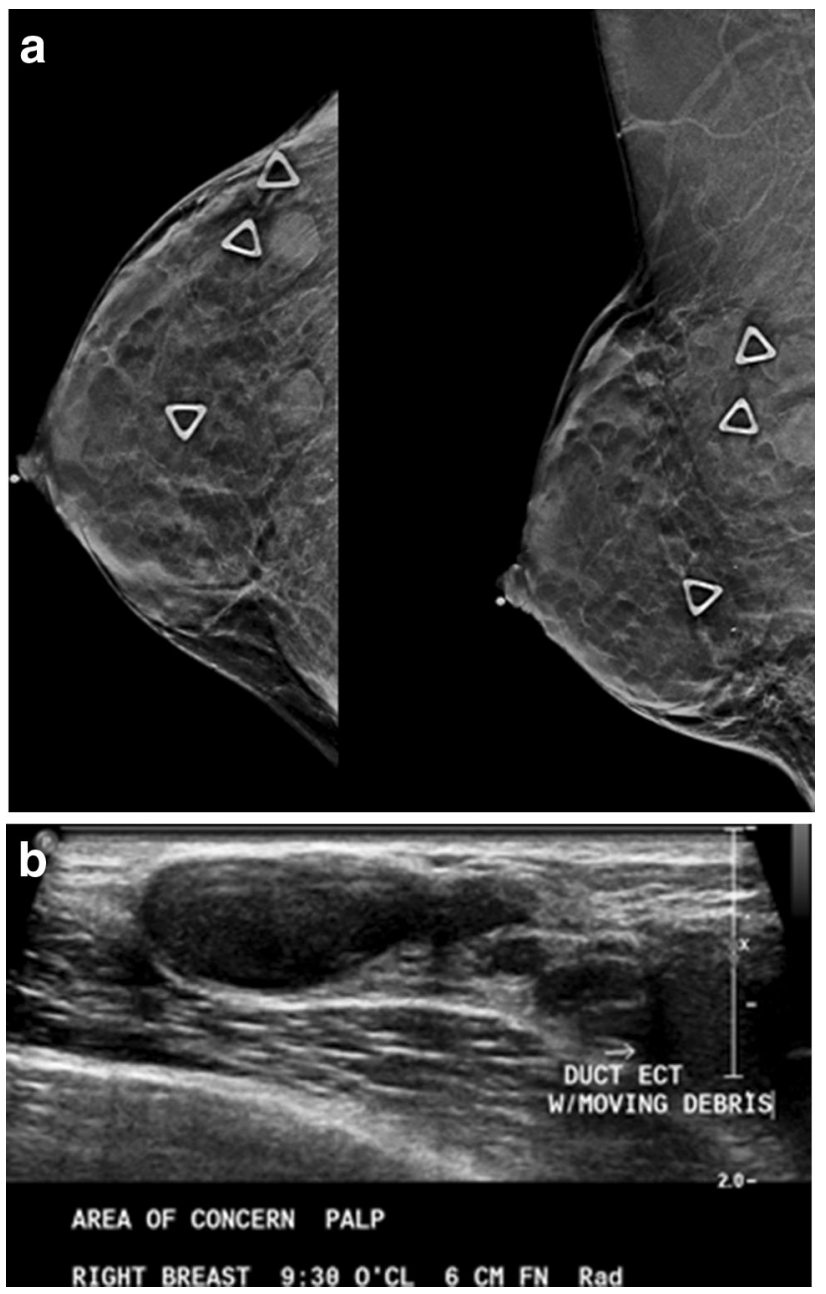

Fig. 4 A 58-year-old transgender woman on hormone treatment complains of lumps in her breast. a CC and MLO mammography views show triangle-shaped skin markers over palpable masses. b Ultrasound shows benign duct ectasia which correlates with the palpable masses

granulomas. Figure 5 shows palpable silicone granulomata which vary in size imaged by mammography, ultrasound and MRI. Free silicone may also create large fibrotic masses in the retroglandular fat and pectoralis muscle which mimic malignancy and obscure breast tissue as displayed in Fig. 6 [33]. Contrast enhanced breast MRI is the preferred mean for detecting cancer in these patient with free particle injections. On breast MRI the granulomas 
are non-enhancing circumscribed T2 high signal with absent signal on T1-weighted fat-suppressed images.

Free oil injections may be detected on cross-sectional imaging. Diffuse circumscribed fat density masses in the chest wall in Fig. 7 are secondary to migration of mineral oil injected into the breast for augmentation purposes.

\section{Hormones and Breast Cancer Risk}

The relationship of altered androgen and estrogen on breast cancer risk is poorly understood. The risk for breast cancer due to exogenous hormones prescribed for transgender individuals is informed by studies of estrogen and androgens in the general population. Use of relatively short-term combined exogenous estrogen and progesterone in postmenopausal cisgender women was associated with increased breast cancer incidence; however, exogenous estrogen alone was not associated with increased risk, according to data from the Women's Health Initiative [34]. According to an analysis of nine prospective studies of endogenous hormone levels and breast cancer risk in postmenopausal women, breast cancer is associated with elevated levels of circulating estrogen and androgens in postmenopausal women [35-37]. Based on these studies, it is reasonable to hypothesize that breast cancer risk might be elevated for transgender women treated with hormone replacement therapy.

Conversely, though there are abundant androgen receptors in normal breast tissue and androgen receptors are also frequently expressed in breast cancers, there is no evidence for increased breast cancer incidence in women with hyperandrogenism such as polycystic ovary syndrome, or in transgender men receiving testosterone treatment [21]. This is somewhat counterintuitive, as there is aromatization of androgens to estrogen in the peripheral blood of transgender men on testosterone, which may result in maintenance of estradiol levels [12]. Breast cancer risk in transgender women is potentially reduced due to a relatively shorter duration of lifetime exposure to estrogen compared to cisgender women. It has been demonstrated that early menarche and late menopause are associated with increased risk of breast cancer in cisgender women [38].

\section{Prospective and Retrospective Cohort Analysis}

It is not possible to derive cancer incidence in transgender individuals from existing U.S. cancer registries because transgender status is not documented. Misclassification of sex/gender assignment in U.S. cancer registries is a wellknown phenomenon which may also result in under reporting of breast cancers in cisgender males [39]. Although there are no population-based studies that document incidence of breast cancer in transgender patients, in a study from the Netherlands following a cohort of 2,307 transgender patients, breast cancer was diagnosed in one transgender male and in two transgender females. The authors calculated that these findings translated into a cancer rate of 4.1 per 100,000 life years in transgender females and 5.9 per 100,000 transgender males, similar to the approximately 1.2 in 100,000 cisgender males and significantly lower than the rate of 170 in 100,000 in cisgender females [40]. These authors concluded that the risk for breast cancer in male to female patients is similar to natal male sex and breast cancer risk in female to male patients also is quite low.

A descriptive study performed in the U.S. published in 2015 measured breast cancer incidence in a cohort of 5,135 transgender veterans [41]. Chart review revealed three cancers in transgender women and seven cancers in transgender men yielding a rate of 20 per 100,000 years. The three transgender women all had advanced disease which the authors use as evidence for the need for screening using standard guidelines. One of the seven transgender men had undergone mastectomy including chest contouring. These data may be unreliable because terminology was not uniform, there was a lack of follow-up outside the VA system, and no specific data on hormone use were provided.

\section{Transgender Women}

Apart from the prospective and retrospective cohorts from the Netherlands and U.S. referred to above, there are a small number of case reports of breast cancers in transgender women. As of 2014, there were ten reported cases of breast cancer in transgender women on hormone treatment. Among those ten cases we observed that age at diagnosis tended to be younger than in cisgender populations, with a median age 48 compared to age 61 in cisgender females. In addition, five out of eight cases had ER negative cancer, and lobular development was similar to that of an adolescent girl [17]. Our series included a case of DCIS detected by screening, one of the few such screen detected cancers in the literature [17]. This highlights the need for more data to assess the role of screening in this population. It is likely that the low incidence of breast cancers is a result of under reporting.

\section{Transgender Men}

It appears that risk for breast cancer in trans men on testosterone treatment is low and it has been hypothesized that testosterone treatment reduces risk [42•]. There are five case reports of breast cancer in transgender men all of whom were treated with testosterone. Of these five cases, 
Fig. 5 A 60-year-old transgender woman with free silicone injections feels a lump. a Mammogram shows multiple high-density masses which are silicone granulomas. The palpable granuloma is designated by blue arrow. b Ultrasound shows the palpable silicone granuloma is a circumscribed anechoic mass (arrow). c The silicone granuloma is a very high signal STIR sequence (arrow). d On a TI post-contrast sequence the silicone granuloma is a nonenhancing circumscribed mass (arrow) circumscribed mass on MRI T2
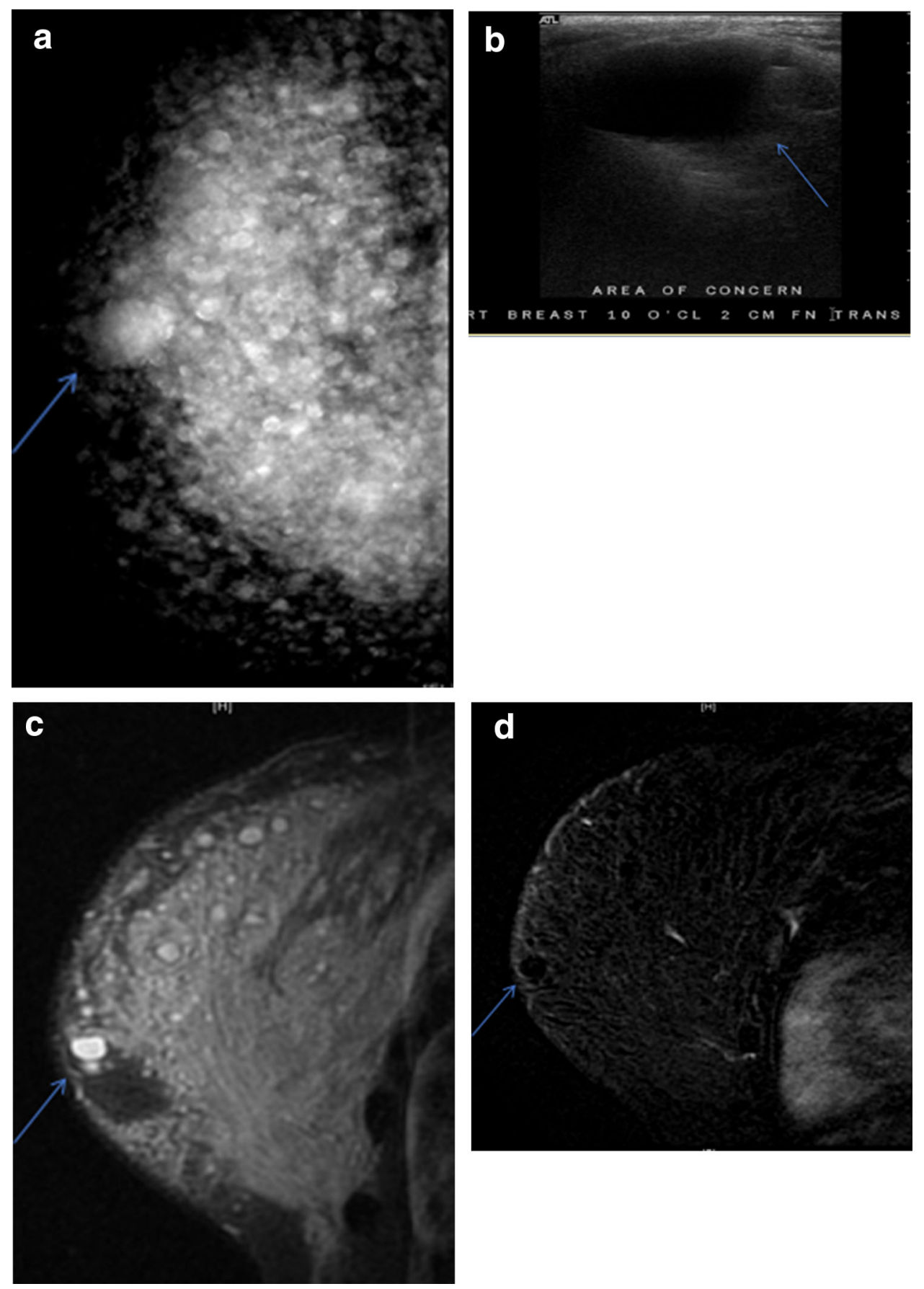

four of the cancers were ER positive and three were PR negative. Invasive duct cancers that were $\mathrm{ER}+\mathrm{PR}$ - were found in two trans men who had not had mastectomy, one at age 27 and the second at age 53 [43]. The three additional invasive duct cancers were residual breast tissue in trans men following subcutaneous mastectomy. One was in the nipple and the second was areolar diagnosed at age 33 following 13 years of hormone treatment and at age 42 following $1 \frac{1}{2}$ years on hormone treatment, respectively
$[44,45]$. The third case is a 41 year old who developed invasive duct carcinoma in the left lower outer quadrant after 15 years on hormone treatment [46]. 
Fig. 6 A 54-year-old

transgender woman is referred for a screening mammography prior to nipple sparing mastectomy to remove painful masses caused by free silicone. a Tomosynthesis shows bilateral large dense masses which are inseparable from the pectoralis muscle (arrows). There are also innumerable small silicone granulomas.

b Ultrasound shows an example of the indistinct hyperechoic "snow storm" appearance of free silicone at posterior depth in both breasts (arrows). c Postcontrast subtracted MRI image shows no suspicious enhancing mass
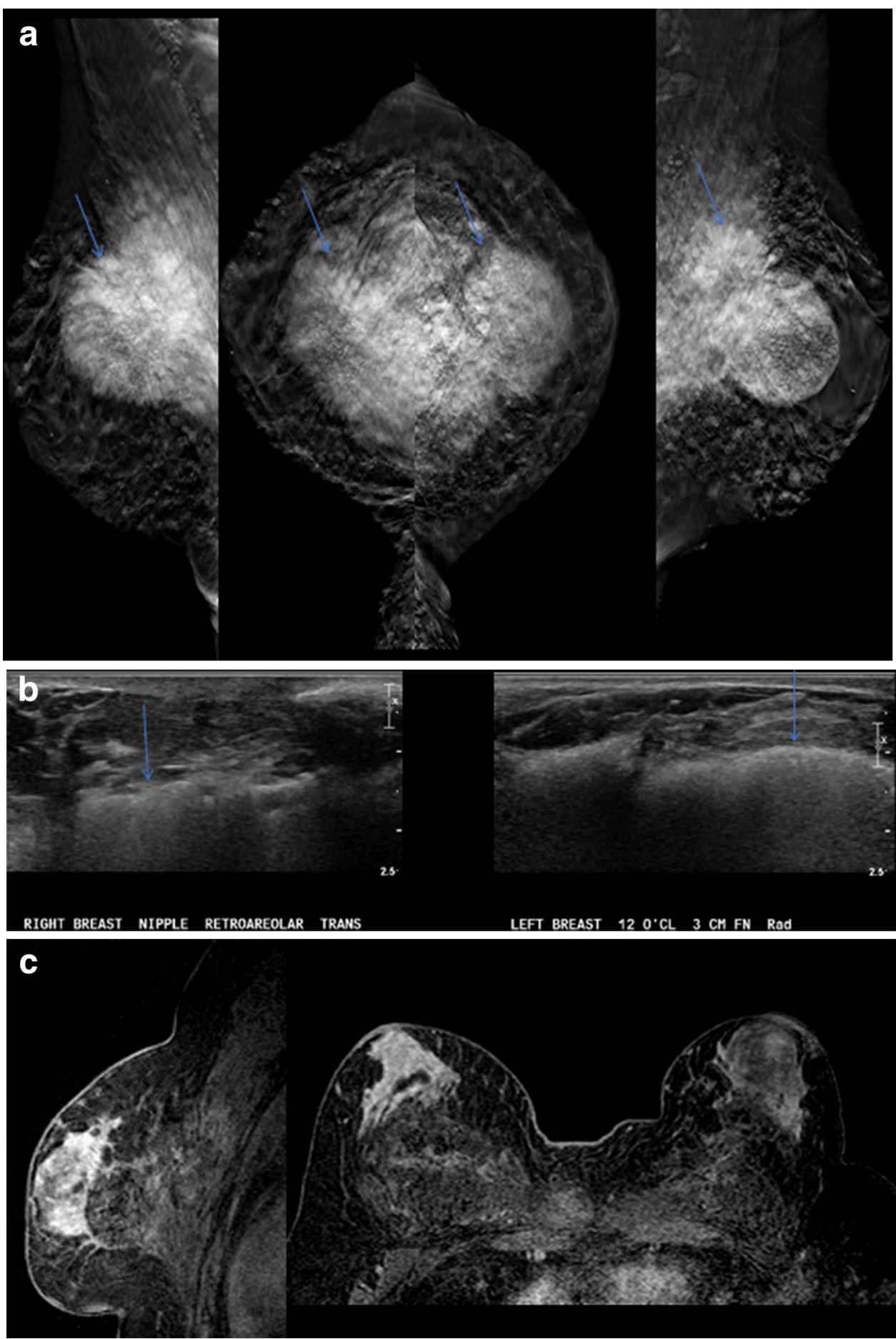

\section{Breast Cancer Screening}

\section{Transgender Men}

It is generally recommended that transgender men who have not had mastectomy or who have only undergone breast reduction should follow the same guidelines for screening mammography as cisgender women irrespective of hormone treatment [47].

While not supported by data, transgender men who have had mastectomy with chest contouring should consider clinical chest exams because, as noted above, cancers have been reported in this setting. Mammography may not be feasible in this group. 
Fig. 7 Chest wall migration of mineral oil incidentally seen on a CT scan in a 41-year-old transgender woman with a history of breast augmentation with free mineral oil selfinjections (arrows)

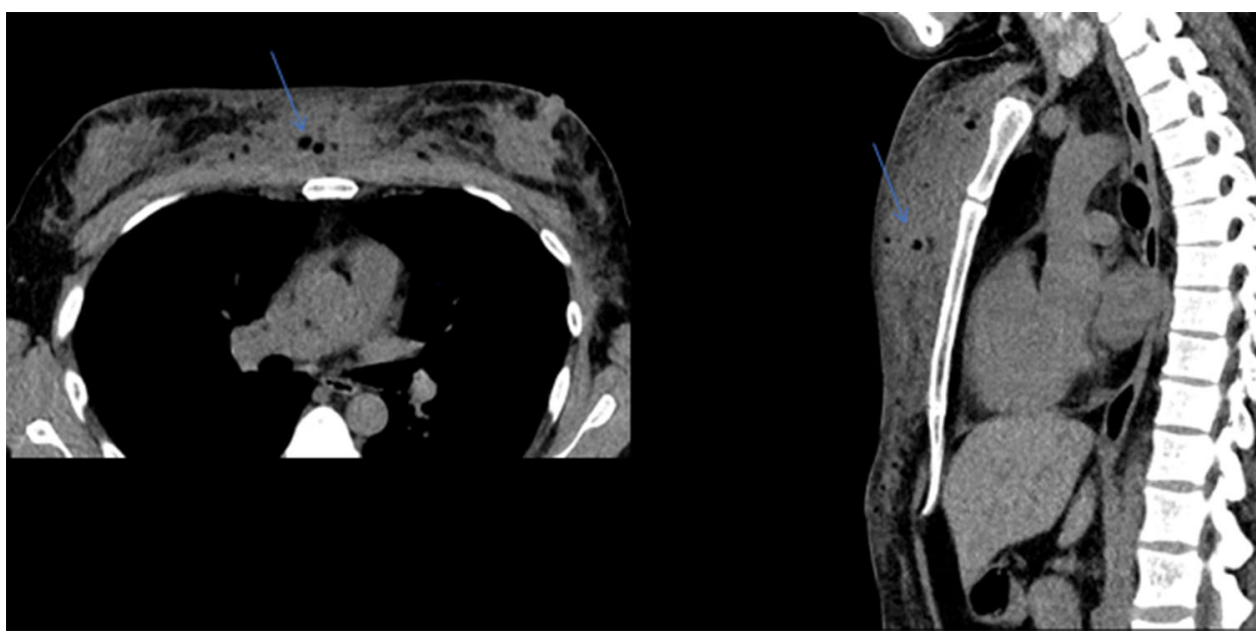

\section{Transgender Women}

There is a lack of consensus among the many organizations that provide recommendations for screening mammography for transgender women who are on hormone treatment. Screening mammography recommendations range from annual or biennial generally starting at age 50 for transgender women who have received estrogen treatment for at least 5 years [47, 48]. Other risk considerations include body mass index over 35 and a family history of breast cancer [47, 48]. Some organizations simply suggest screening all transgender women identically to cisgender women [7•]. There is no evidence base for these recommendations.

There are limited conflicting observations of utilization of mammography by transgender individuals. Using phone surveys conducted in 2014 by the Center for Disease Control's Behavioral Risk Factor Surveillance System including 220 respondents, $54.5 \%$ of transgender females and $64.3 \%$ of transgender male respondents had undergone mammography within the past year [49]. This study lacked information about hormone and surgical treatment and involved a small number of participants. A small retrospective study which compared mammography utilization between cisgender women, transgender women on at least 5 years of hormone treatment, and preoperative transgender men at a single urban health center, observed decreased utilization of mammography by both transgender men and women [50].

\section{Additional Risk Considerations}

While any patient with breast tissue may develop breast cancer, risks vary according to genotype, phenotype, and acquired risk factors due to certain exposures. Table 2 outlines risks and screening recommendations for various groups. It is important for transgender individuals to receive detailed genetic risk assessment based on family history of breast, ovarian, prostate, and/or pancreatic cancer and ancestry (e.g., Ashkenazi heritage), as these factors correlate with incidence of breast cancer susceptibility mutations. A major driver of risk for breast cancer is inherited mutations of genes such as BRCA2, BRCA1 and more rarely PALB2 and CHEK2 [51]. While cisgender men have a lifetime risk for breast cancer of $0.1 \%$, those with Klinefelter's syndrome or a deleterious mutation of the BRCA2 gene have an elevated lifetime risk for breast cancer of $5-7 \%[52,53]$. How hormone treatment might alter risk in the setting of a deleterious gene mutation remains to be determined. It has been suggested that transgender women with a BRCA gene mutation should use the same screening guidelines as cisgender mutation carriers [54].

Because there is no evidence base for screening recommendations, any recommended screening should be done as part of an ongoing prospective study. We have initiated one such effort in New York, which is open to any individual seeking more information [55]. Additional prospective data pertaining to transgender populations incorporating phenotype, genotype, acquired risks, hormone exposure, and correlating radiographic features and clinical outcome is critically needed to develop riskadapted breast cancer screening protocols in this population.

\section{Conclusion}

Radiologists need to be knowledgeable about hormone and surgical treatments for transgender individuals that influence imaging appearance and risk for breast diseases. Imaging should be performed in a culturally sensitive 
Table 2 Breast cancer risk and screening recommendations

\begin{tabular}{|c|c|c|c|c|}
\hline Group & $\begin{array}{l}\text { Lifetime risk for } \\
\text { breast cancer }\end{array}$ & $\begin{array}{l}\text { Suggested ages to start } \\
\text { mammography per various } \\
\text { guidelines }\end{array}$ & Interval & Note \\
\hline $\begin{array}{l}\text { Cisgender women at average } \\
\text { risk }\end{array}$ & $12 \%$ & $\begin{array}{l}\text { Age } 40[56] \\
\text { Age } 50[57]\end{array}$ & $\begin{array}{l}\text { Annual } \\
\text { [56] } \\
\text { Biennial } \\
\text { [57] }\end{array}$ & $\begin{array}{l}\text { Recommendations on age to start and } \\
\text { interval varies across organizations }\end{array}$ \\
\hline Cisgender men at average risk & $0.1 \%$ & N/A & N/A & \\
\hline $\begin{array}{l}\text { Transgender women on at least } \\
5 \text { years of hormone treatment }\end{array}$ & $\begin{array}{l}\text { Slightly higher } \\
\text { than cisgender } \\
\text { men }\end{array}$ & $\begin{array}{l}50[48] \\
50[49] \\
\text { Follow non-transgender } \\
\quad \text { guidelines }[7,59]\end{array}$ & $\begin{array}{l}\text { Biennial } \\
\text { [48] } \\
\text { Annual } \\
\text { [49] }\end{array}$ & $\begin{array}{l}\text { Consider additional risk factors: } \\
\text { BMI }>35 \text {, family history of breast } \\
\text { cancer }[48,49]\end{array}$ \\
\hline $\begin{array}{l}\text { Transgender men without } \\
\text { mastectomy (no "top } \\
\text { surgery") }\end{array}$ & $12 \%$ & $\begin{array}{l}\text { Same recommendation as } \\
\text { cisgender women [47] }\end{array}$ & Annual & $\begin{array}{l}\text { Risk may vary with hormone treatment or } \\
\text { oophorectomy }\end{array}$ \\
\hline Klinefelter's syndrome [52] & $3-7.5 \%$ & N/A & N/A & $\begin{array}{l}\text { Consider annual clinical breast exam } \\
\text { (CBE) at age } 35[60]\end{array}$ \\
\hline $\begin{array}{l}\text { Transgender men post top } \\
\text { surgery on hormone } \\
\text { treatment }\end{array}$ & $\begin{array}{l}\text { Slightly higher } \\
\text { than cisgender } \\
\text { male }\end{array}$ & N/A & N/A & $\begin{array}{l}\text { Chest awareness. } \\
\text { Annual chest wall and axillary exam [58] }\end{array}$ \\
\hline $\begin{array}{l}\text { Cisgender men w BRCA2 gene } \\
\text { mutation [53] }\end{array}$ & $5-7 \%$ & N/A & N/A & $\begin{array}{l}\text { Breast awareness. Annual CBE at age } 35 \\
\text { [58] }\end{array}$ \\
\hline $\begin{array}{l}\text { Cisgender men w BRCA1 gene } \\
\text { mutation [53] }\end{array}$ & $1.2 \%$ & N/A & N/A & \\
\hline $\begin{array}{l}\text { Cisgender women w BRCA } 1 \\
\text { or } 2 \text { gene mutation [53] }\end{array}$ & $26-91 \%(>20 \%)$ & Age 25 & Annual & $\begin{array}{l}\text { Annual CBE at age } 25 \text { [58] Annual breast } \\
\text { MRI starting at age } 25 \text { [58] }\end{array}$ \\
\hline
\end{tabular}

environment. The current recommendations for mammography screening are based on data from cisgender women. Additional data, specifically from prospective longitudinal follow-up of transgender individuals electing breast cancer radiologic surveillance is needed to understand breast cancer risk in this population and to develop appropriate risk-adapted screening protocols. We have initiated one such effort in New York.

Acknowledgements The authors would like to thank Samantha Walsh for assistance in preparation of this manuscript, Dr. Laurie Margolies and The Morris and Anna Propp Sons Fund.

\section{Compliance with Ethical Standards}

Conflict of interest Emily B. Sonnenblick, Ami D. Shah, Zil Goldstein, and Tamar Reisman each declare no potential conflicts of interest.

Human and Animal Rights and Informed Consent This article does not contain any studies with human or animal subjects performed by any of the authors.

Open Access This article is distributed under the terms of the Creative Commons Attribution 4.0 International License (http:// creativecommons.org/licenses/by/4.0/), which permits unrestricted use, distribution, and reproduction in any medium, provided you give appropriate credit to the original author(s) and the source, provide a link to the Creative Commons license, and indicate if changes were made.

\section{References}

Recently published papers of particular interest have been highlighted as:

- Of importance

- Of major importance

1. • Winter S, Diamond M, Green J, Karasic D, Reed T, Whittle S, et al. Transgender people: health at the margins of society. Lancet. 2016;388(10042):390-400. Review of epidemiology and barriers faced by transgender population.

2. Glossary of Gender and Transgender Terms: Fenway Health website; 2010 [updated 2010. Available from: http:// fenwayhealth.org/documents/the-fenway-institute/handouts/ Handout_7-C_Glossary_of_Gender_and_Transgender_Terms_ fi.pdf.

3. Bradford J, Reisner SL, Honnold JA, Xavier J. Experiences of transgender-related discrimination and implications for health: results from the Virginia Transgender Health Initiative Study. Am J Public Health. 2013;103(10):1820-9.

4. Safer JD, Coleman E, Feldman J, Garofalo R, Hembree W, Radix A, et al. Barriers to healthcare for transgender individuals. Curr Opin Endocrinol Diabetes Obes. 2016;23(2):168-71.

5. Wylie K, Knudson G, Khan SI, Bonierbale M, Watanyusakul S, Baral S. Serving transgender people: clinical care considerations and service delivery models in transgender health. Lancet. 2016;388(10042):401-11.

6. Fabris B, Bernardi S, Trombetta C. Cross-sex hormone therapy for gender dysphoria. J Endocrinol Invest. 2015;38(3):269-82. 
7. - Hembree WC, Cohen-Kettenis PT, Gooren L, Hannema SE, Meyer WJ, Murad MH, et al. Endocrine Treatment of GenderDysphoric/Gender-Incongruent Persons: An Endocrine Society Clinical Practice Guideline. J Clin Endocrinol Metabol. 2017;102(11):1-35. Recently updated evidence based guide to clinical care of transgender people.

8. Marshall WA, Tanner JM. Variations in pattern of pubertal changes in girls. Arch Dis Child. 1969;44(235):291-303.

9. - Wierckx K, Gooren L, T'Sjoen G. Clinical review: Breast development in trans women receiving cross-sex hormones. J Sex Med. 2014;11(5):1240-7. Although data is sparse this is a good review of hormone induced breast development in transgender women.

10. Seal LJ, Franklin S, Richards C, Shishkareva A, Sinclaire C, Barrett J. Predictive markers for mammoplasty and a comparison of side effect profiles in transwomen taking various hormonal regimens. J Clin Endocrinol Metab. 2012;97(12):4422-8.

11. Deutsch MB, Bhakri V, Kubicek K. Effects of cross-sex hormone treatment on transgender women and men. Obstet Gynecol. 2015;125(3):605-10.

12. Spinder T, Spijkstra JJ, van den Tweel JG, Burger CW, van Kessel H, Hompes PG, et al. The effects of long term testosterone administration on pulsatile luteinizing hormone secretion and on ovarian histology in eugonadal female to male transsexual subjects. J Clin Endocrinol Metab. 1989;69(1):151-7.

13. Rebbeck TR, Friebel T, Lynch HT, Neuhausen SL, van 't Veer L, Garber JE, et al. Bilateral prophylactic mastectomy reduces breast cancer risk in BRCA1 and BRCA2 mutation carriers: the PROSE Study Group. J Clin Oncol. 2004;22(6):1055-62.

14. Braunstein GD. Clinical practice. Gynecomastia N Engl J Med. 2007;357(12):1229-37.

15. Appelbaum AH, Evans GF, Levy KR, Amirkhan RH, Schumpert TD. Mammographic appearances of male breast disease. Radiographics. 1999;19(3):559-68.

16. Kanhai RC, Hage JJ, van Diest PJ, Bloemena E, Mulder JW. Short-term and long-term histologic effects of castration and estrogen treatment on breast tissue of 14 male-to-female transsexuals in comparison with two chemically castrated men. Am J Surg Pathol. 2000;24(1):74-80.

17. Maglione KD, Margolies L, Jaffer S, Szabo J, Schmidt H, Weltz $\mathrm{C}$, et al. Breast cancer in male-to-female transsexuals: use of breast imaging for detection. AJR Am J Roentgenol. 2014;203(6):W735-40.

18. Slagter MH, Gooren LJ, Scorilas A, Petraki CD, Diamandis EP. Effects of long-term androgen administration on breast tissue of female-to-male transsexuals. J Histochem Cytochem. 2006;54(8):905-10.

19. Sapino A, Pietribiasi F, Godano A, Bussolati G. Effect of longterm administration of androgens on breast tissues of female-tomale transsexuals. Ann N Y Acad Sci. 1990;586:143-5.

20. Burgess HE, Shousha S. An immunohistochemical study of the long-term effects of androgen administration on female-to-male transsexual breast: a comparison with normal female breast and male breast showing gynaecomastia. J Pathol. 1993;170(1):37-43.

21. Grynberg M, Fanchin R, Dubost G, Colau JC, Bremont-Weil C, Frydman R, et al. Histology of genital tract and breast tissue after long-term testosterone administration in a female-to-male transsexual population. Reprod Biomed Online. 2010;20(4):553-8.

22. Kanhai RC, Hage JJ, Bloemena E, van Diest PJ, Karim RB. Mammary fibroadenoma in a male-to-female transsexual. Histopathology. 1999;35(2):183-5.

23. Lemmo G, Garcea N, Corsello S, Tarquini E, Palladino T, Ardito $\mathrm{G}$, et al. Breast fibroadenoma in a male-to-female transsexual patient after hormonal treatment. Eur J Surg Suppl. 2003;588:69-71.
24. Walsh CM, Yang L, Park JM, Askeland RW, Fajardo LL. Angiolipoma of the breast in a transgender patient. Breast J. 2014;20(6):662-3.

25. Lee JW, Nadelman CM, Hirschowitz SL, Debruhl ND, Bassett LW. Malignant phyllodes tumor of a genotypic male, phenotypic female with liposarcomatous differentiation. Breast $\mathrm{J}$. 2007;13(3):312-3

26. Phillips J, Fein-Zachary VJ, Mehta TS, Littlehale N, Venkataraman S, Slanetz PJ. Breast imaging in the transgender patient. AJR Am J Roentgenol. 2014;202(5):1149-56.

27. Weyers S, Villeirs G, Vanherreweghe E, Verstraelen H, Monstrey S, Van den Broecke R, et al. Mammography and breast sonography in transsexual women. Eur J Radiol. 2010;74(3):508-13.

28. Harvey JA, Mahoney MC, Newell MS, Bailey L, Barke LD, D’Orsi C, et al. ACR Appropriateness Criteria Palpable Breast Masses. J Am Coll Radiol. 2016;13(11S):e31-42.

29. Yang N, Muradali D. The augmented breast: a pictorial review of the abnormal and unusual. AJR Am J Roentgenol. 2011;196(4):W451-60.

30. Hazani R, Engineer N. Surreptitious injection of mineral oil: a case report of sclerosing lipogranulomatosis. Ann Plast Surg. 2008;61(5):555-8.

31. Chen M, Yalamanchili C, Hamous J, Piskun MA, Weis B. Acute inflammatory response of the male breasts secondary to self-injection of petroleum jelly: a case report. South Med J. 2008;101(4):422-4.

32. Erguvan-Dogan B, Yang WT. Direct injection of paraffin into the breast: mammographic, sonographic, and MRI features of early complications. AJR Am J Roentgenol. 2006;186(3):888-94.

33. Han BK, Choe YH, Ko YH, Nam SJ, Yang JH. Foreign body granulomas of the breast presenting as bilateral spiculated masses. Korean J Radiol. 2001;2(2):113-6.

34. Chlebowski RT, Hendrix SL, Langer RD, Stefanick ML, Gass M, Lane D, et al. Influence of estrogen plus progestin on breast cancer and mammography in healthy postmenopausal women: the Women's Health Initiative Randomized Trial. JAMA. 2003;289(24):3243-53.

35. Key T, Appleby P, Barnes I, Reeves G, Endogenous H, Breast Cancer Collaborative G. Endogenous sex hormones and breast cancer in postmenopausal women: reanalysis of nine prospective studies. J Natl Cancer Inst. 2002;94(8):606-16.

36. Missmer SA, Eliassen AH, Barbieri RL, Hankinson SE. Endogenous estrogen, androgen, and progesterone concentrations and breast cancer risk among postmenopausal women. J Natl Cancer Inst. 2004;96(24):1856-65.

37. Manson JE, Chlebowski RT, Stefanick ML, Aragaki AK, Rossouw JE, Prentice RL, et al. Menopausal hormone therapy and health outcomes during the intervention and extended poststopping phases of the Women's Health Initiative randomized trials. JAMA. 2013;310(13):1353-68.

38. Pike MC, Spicer DV, Dahmoush L, Press MF. Estrogens, progestogens, normal breast cell proliferation, and breast cancer risk. Epidemiol Rev. 1993;15(1):17-35.

39. Sherman RL, Boscoe FP, O'Brien DK, George JT, Henry KA, Soloway LE, et al. Misclassification of sex in central cancer registries. J Registry Manag. 2014;41(3):120-4.

40. Gooren LJ, van Trotsenburg MA, Giltay EJ, van Diest PJ. Breast cancer development in transsexual subjects receiving cross-sex hormone treatment. J Sex Med. 2013;10(12):3129-34.

41. Brown GR, Jones KT. Incidence of breast cancer in a cohort of 5,135 transgender veterans. Breast Cancer Res Treat. 2015;149(1):191-8.

42. - Irwig MS. Testosterone therapy for transgender men. Lancet Diabetes Endocrinol. 2017;5(4):301-11. Long term European observation of breast cancer incidence in transgender population where care is centralized. 
43. Shao T, Grossbard ML, Klein P. Breast cancer in female-to-male transsexuals: two cases with a review of physiology and management. Clin Breast Cancer. 2011;11(6):417-9.

44. Burcombe R, Makris A, Pittam M, Finer N. Breast cancer after bilateral subcutaneous mastectomy in a female-to-male transsexual. The Breast. 2003;12(4):290-3.

45. Nikolic DV, Djordjevic ML, Granic M, Nikolic AT, Stanimirovic $\mathrm{VV}$, Zdravkovic D, et al. Importance of revealing a rare case of breast cancer in a female to male transsexual after bilateral mastectomy. World J Surg Oncol. 2012;10:280.

46. Katayama Y, Motoki T, Watanabe S, Miho S, Kimata Y, Matsuoka J, et al. A very rare case of breast cancer in a female-tomale transsexual. Breast Cancer. 2016;23(6):939-44.

47. Center of Excellence for Transgender Health DoFaCM, UCSF. Guidelines for the Primary and Gender-Affirming Care of Transgender and Gender Nonbinary People: Center of Excellence for Transgender Health, Department of Family and Community Medicine University of California San Francisco; 2016 2nd: www.transhealth.ucsf.edu/guidelines.

48. Makadon HJ, Mayer KH, Potter J, Goldhammer H, American College of P. The Fenway guide to lesbian, gay, bisexual, and transgender health2015.

49. Narayan A, Lebron-Zapata L, Morris E. Breast cancer screening in transgender patients: findings from the 2014 BRFSS survey. Breast Cancer Res Treat. 2017.

50. Bazzi AR, Whorms DS, King DS, Potter J. Adherence to Mammography Screening Guidelines Among Transgender Persons and Sexual Minority Women. Am J Public Health. 2015;105(11):2356-8.

51. Easton DF, Pharoah PD, Antoniou AC, Tischkowitz M, Tavtigian $\mathrm{SV}$, Nathanson KL, et al. Gene-panel sequencing and the prediction of breast-cancer risk. $\mathrm{N}$ Engl $\mathrm{J}$ Med. 2015;372(23):2243-57.

52. Hultborn R, Hanson C, Kopf I, Verbiene I, Warnhammar E, Weimarck A. Prevalence of Klinefelter's syndrome in male breast cancer patients. Anticancer Res. 1997;17(6D):4293-7.

53. Silvestri V, Barrowdale D, Mulligan AM, Neuhausen SL, Fox S, Karlan BY, et al. Male breast cancer in BRCA1 and BRCA2 mutation carriers: pathology data from the Consortium of Investigators of Modifiers of BRCA1/2. Breast Cancer Res. 2016;18(1):15.

54. Colebunders B, T'Sjoen G, Weyers S, Monstrey S. Hormonal and surgical treatment in trans-women with BRCA1 mutations: a controversial topic. J Sex Med. 2014;11(10):2496-9.

55. Open Clinical Trials at the Dubin Breast Center, Mount Sinai Hospital New York: Mount Sinai Hospital; 2017 [Available from: http://www.mountsinai.org/patient-care/service-areas/cancer/ cancer-services/dubin-breast-center/breast-cancer-research/ clinical-trials.

56. Mainiero MB, Lourenco A, Mahoney MC, Newell MS, Bailey L, Barke LD, et al. ACR Appropriateness criteria breast cancer screening. J Am Coll Radiol. 2016;13(11S):R45-R9

57. Siu AL, Force USPST. Screening for breast cancer: U.S. Preventive Services Task Force Recommendation Statement. Ann Intern Med. 2016;164(4):279-96

58. Genetic/familial high risk assessment: breast and ovarian. National Comprehensive Cancer Network; 2017 Version 2.2017

59. American College of Obstetricians and Gynecologists. Health care for transgender individuals. Committee Opinion No. 512. Obstet Gynecol. 2011;118:1454-8

60. Brinton L. Breast cancer risk among Klinefelter syndrome patients. Acta Paediatr. 2011;100(6):814-8 